\title{
A CASE REPORT- EPIDERMODYSPLASIA VERRUCIFORMIS IN AN IMMUNODEFICIENT CHILD
}

\author{
Kallappa Herakal1, Mouryabha Shale K. S2, Karjigi Siddalingappa³, Pethani Parag Vallabhbhai4, Deepika M. G5 \\ 1 Professor and HOD, Department of Dermatology, Navodaya Medical College and Hospital and Research Centre. \\ 2Junior Resident, Department of Dermatology, Navodaya Medical College and Hospital and Research Centre. \\ 3 Professor, Department of Dermatology, Navodaya Medical College and Hospital and Research Centre. \\ 4Junior Resident, Department of Dermatology, Navodaya Medical College and Hospital and Research Centre. \\ 5Junior Resident, Department of Dermatology, Navodaya Medical College and Hospital and Research Centre.
}

\section{ABSTRACT}

\section{BACKGROUND}

Epidermodysplasia verruciformis (EV) is a rare, lifelong, cutaneous, autosomal recessive genetic disorder of the immune system manifested by increased susceptibility to cutaneous Human Papilloma Virus (HPV) infection beginning in the early years of life. EV lesions are frequently described as pityriasis versicolor-like scaly macules, flat warts like papules or verrucous and seborrhoeic keratosis like papules and plaques. Here, we report a case of 14 years old boy who presented to us with multiple hyperkeratotic papules over face and upper extremities since 2 years. Hypopigmented macules over face, neck, upper chest and trunk since 4 months. Patient was treated topically with cryotherapy and systemically with acitretin and immunomodulators for warts and pityriasis versicolor was treated with topical and oral antifungals.

\section{KEYWORDS}

Epidermodysplasia Verruciformis, Human Papilloma Virus, Pityriasis Versicolor, Seborrhoeic Keratosis, Cryotherapy, Acitretin.

HOW TO CITE THIS ARTICLE: Herakal K, Shale MKS, Siddalingappa K, et al. A case report- epidermodysplasia verruciformis in an immunodeficient child. J. Evolution Med. Dent. Sci. 2017;6(23):1947-1949, DOI: 10.14260/Jemds/2017/426

\section{BACKGROUND}

Epidermodysplasia verruciformis (EV) is a rare, generalised, persistent, inherited disorder that predisposes the patient to widespread HPV infection and cutaneous malignancies. ${ }^{1}$ The term "acquired EV" describes a syndrome nearly identical to congenital EV that afflicts immunocompromised patients. ${ }^{2}$

In EV, there are mutations in the EVER1 or EVER2 genes on the chromosomes $17 q 25$, which due to defect of cell mediated immunity lead to an abnormal susceptibility of the patients to a specific group of HPV genotypes known as EV HPV. Most of these are HPV 5 and 8, more rarely HPV 14, 17, 20 and 47 and all have oncogenic potential. ${ }^{3}$

EV usually begins in infancy or early childhood, but may appear at any age. The cutaneous lesions are mainly flat warts, reddish-brown scaly macules resembling tinea versicolor or pityriasis rosea. ${ }^{4}$ The lesions mainly occur on sun-exposed area, but may be generalised all over the body. Oral mucosa is spared.

Cutaneous nonmelanoma skin cancers developed in 30\% to $50 \%$ of the patients within mean of 25 years after the onset of benign skin lesions. ${ }^{5}$ These cancers are mostly Bowen's disease and invasive squamous cell carcinomas, growing slowly on areas exposed to sunlight.

Financial or Other, Competing Interest: None.

Submission 04-02-2017, Peer Review 04-03-2017,

Acceptance 13-03-2017, Published 20-03-2017.

Corresponding Author:

Dr. Kallappa Herakal,

Professor and HOD,

Department of Dermatology,

Navodaya Medical College and Hospital

\& Research Centre, Mantralaya Road,

Raichur.

E-mail: mouryabha@gmail.com

DOI: $10.14260 /$ jemds $/ 2017 / 426$

\section{Case Report}

A 14 years old boy was admitted in Department of Paediatrics for fever and upper respiratory tract infection. He was referred to our OPD for recurrent Herpes simplex labialis since 1 year. He was treated with antiviral drugs and antibiotics.

The physical examination reveals multiple hyperpigmented keratotic papules over the face and upper extremities since 2 years. Irregular hypopigmented macules were present over face, neck, upper chest and trunk since 4 months. Also, there was presence of multiple fluid filled lesions with crusting near the angle of mouth. There was also presence of recurrent multiple fluid filled lesions near the angle of mouth 4 - 5 episodes per year associate with pain. No clinical signs of squamous cell carcinoma, no history of similar complaints in the family.

A biopsy of a papule was taken from the forearm. Microscopic examination revealed epidermal acanthosis, hyperkeratosis, vacuolation of superficial keratinocytes in the granular layer and mild perivascular infiltrate in the superficial dermis. These findings are consistent with verruca plana.

On laboratory investigation, complete haemogram reveals anaemia and leucopaenia. HIV and HBsAg tests were negative. Patient was treated topically with cryotherapy for once in a week for 1 month. Systemically with acitretin at the dose of $10 \mathrm{mg}$ /day and immunomodulators levamisole 150 mg on two consecutive days in a week for warts. Topical Eberconazole twice a day application and oral Itraconazole $100 \mathrm{mg}$ twice a day for a week for Pityriasis Versicolor. Topical fusidic acid twice a day application and oral acyclovir $400 \mathrm{mg}$ thrice a day for 5 days for herpes labialis. 

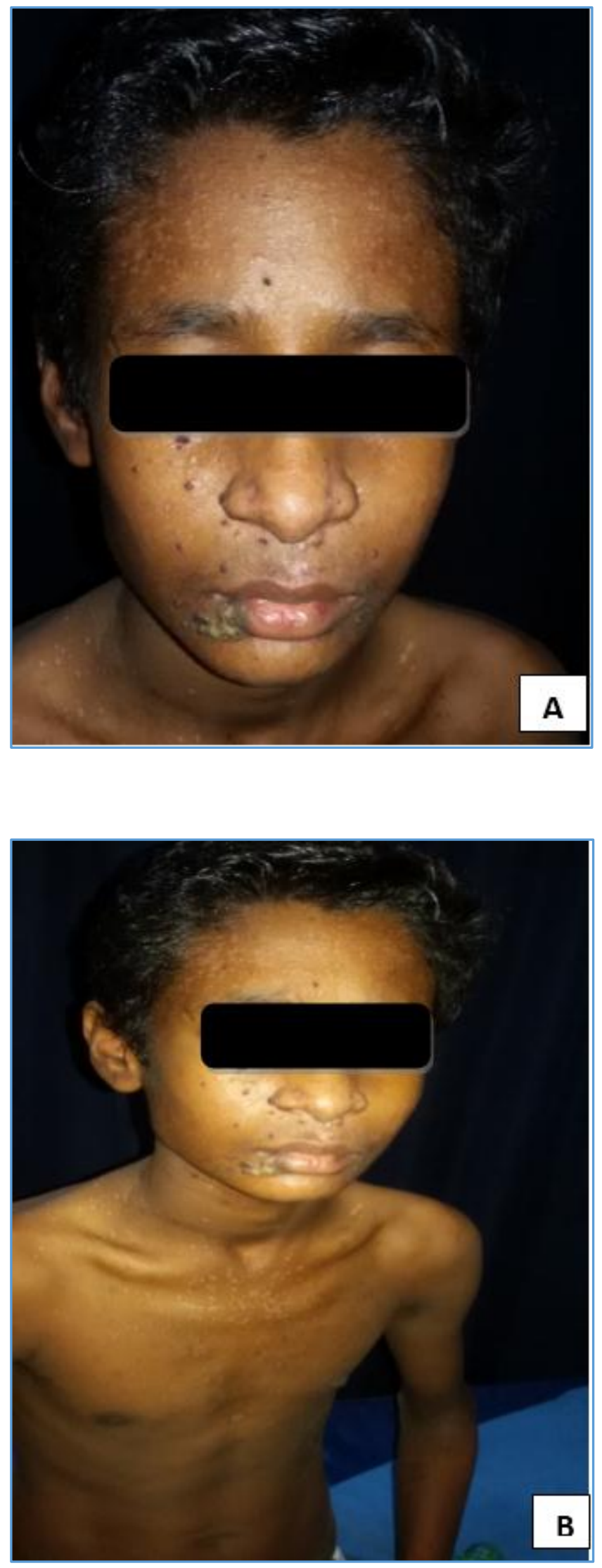

A) Multiple Hyperpigmented Keratotic Papules over the Face and Presence of Multiple Fluid Filled Lesions with Crusting Near Angle of Mouth. B) Irregular

Hypopigmented Macules were Present over Face, Neck and Upper Chest

\section{DISCUSSION}

Epidermodysplasia verruciformis (EV) is a rare, generalised, persistent, inherited disorder that predisposes the patient to widespread HPV infection and cutaneous malignancies. ${ }^{1}$ Although, it has an autosomal recessive transmission in most cases, $\mathrm{X}$-linked recessive and autosomal dominant forms also exist. 6

The disease was first described by Lewandowski and Lutz in 1922 and is characterised by both impaired immunity and viral oncogenesis. ${ }^{7}$ The term "acquired EV" has been used to describe a condition with clinical features similar to EV that occurs in immunocompromised patients, specifically those with HIV or those on immunosuppressive therapy. ${ }^{2}$ In EV, there are mutations in the EVER1 or EVER2 genes on the chromosomes 17q25, which due to defect of cell mediated immunity lead to an abnormal susceptibility of the patients to a specific group of HPV genotypes known as EV HPV. Most of these are HPV 5 and 8, more rarely HPV 14, 17, 20 and 47 and all have oncogenic potential. ${ }^{3}$

HPV 5 and HPV 8 have been isolated in more than $90 \%$ of EV-associated squamous cell carcinomas. Two loci on chromosomes 17q25 and 2p21-p24 are associated with EV in some families. Many HPV types found in EV lesions are nonpathogenic to the general population. EV is universal and affects all races. It typically presents in childhood, but congenital forms are known. Malignant change occur in $20 \%$ $30 \%$ cases, more commonly in fourth and fifth decade.

The classic histological finding of epidermodysplasia verruciformis is a verruca plana-type lesion with mild-tomoderate hyperkeratosis, acanthosis and enlarged vacuolated keratinocytes with perinuclear halos and bluegray cytoplasmic pallor. ${ }^{8}$ Pre-malignant lesions display features similar to actinic keratosis with prominent atypical dyskeratotic cells. Malignant tumours most commonly show squamous and occasionally adnexal differentiation. ${ }^{9}$

EV usually begins in infancy or early childhood, but may appear at any age. The cutaneous lesions are mainly flat warts, reddish-brown scaly macules resembling tinea versicolor or pityriasis rosea. ${ }^{4}$ The lesions mainly occur on sun-exposed area, but may be generalised all over the body. Oral mucosa is spared. EV lesions are remarkably persistent and may remain unchanged for decades. Though impairment of cell immunity is found in EV, patients are not susceptible to other viral and bacterial infections.

Cutaneous nonmelanoma skin cancers developed in $30 \%$ to $50 \%$ of the patients, within mean of 25 years after the onset of benign skin lesions. 5 These cancers are mostly Bowen's disease and invasive squamous cell carcinomas, growing slowly on areas exposed to sunlight.

However, nowadays, malignant conversion is seen over shorter periods of time, possibly due to the increase of time to sun exposure, altitude or outdoor occupations. ${ }^{10}$ Therefore, malignancies start to appear well before 40 years of age. The lesions appear mainly on sun-exposed areas, frequently on the forehead. This could be explained by the combination of chronic ultraviolet exposure and probable presence of oncogenic EV-HPV in hair follicles. Ultraviolet and x-rays are cocarcinogens. Metastasis in these cases is very rare, if there is no history of radiation therapy. ${ }^{11}$

Sun exposure can greatly hasten time to malignant transformation. If a patient with EV is living at a high altitude 
and/or works outdoor and does not use sunscreen, malignant transformation can be seen earlier in the disease progression. Treatment of EV remains challenging. Patients should be routinely monitored for the development of cutaneous cancers, because of its malignant potential. ${ }^{7}$ Sun avoidance and photoprotection are also recommended. Etretinate 1 $\mathrm{mg} / \mathrm{kg} /$ day is helpful in some cases, but the lesions recur. ${ }^{12}$

Oral isotretinoin is also effective. Topical imiquimod, calcipotriol and squaric acid dibutyl ester have been found to be effective in individual cases. ${ }^{13}$

Electrocautery and cryotherapy are used in the treatment of benign and premalignant skin lesions. Although more radical than pharmacological treatment, surgical treatment is considered more effective. Complete excision and defect reconstruction with split-thickness or full-thickness skin grafts or local flaps are the preferred approaches.

\section{REFERENCES}

[1] Rady PL, De Oliveira WR, He Q, et al. Novel homozygous nonsense TMC8 mutation detected in patients with epidermodysplasia verruciformis from a Brazilian family. J Invest Dermatol 2007;157(4):8313.

[2] Rodgers HD, Macgregor JL, Nord KM, et al. Acquired epidermodysplasia verruciformis. J Am Acad Dermatol 2009;60(2):315-20.

[3] Ramoz N, Taieb A, Rueda LA, et al. Evidence for a nonallelic heterogeneity of epidermodysplasia verruciformis with two susceptibility loci mapped to chromosome regions 2p21-p24 and 17q25. J Invest Dermatol 2000;114(6):1148-53.

[4] Gul U, Killic A, Gonul M, et al. Clinical aspects of epidermodysplasia verruciformis and review of the literature. Int J Dermatol 2007;46(10):1069-72.
[5] Lutzner MA. Epidermodysplasia verruciformis. An autosomal recessive disease characterized by viral warts and skin cancer. A model for viral oncogenesis. Bull cancer 1978;65(2):169-82.

[6] Gubinelli E, Posteraro P, Cocuroccia B, et al. Epidermodysplasia verruciformis with multiple mucosal carcinomas treated with pegylated interferon alfa and acitretin. Journal of Dermatological Treatment 2003;14(3):184-8.

[7] Patel T, Morrison LK, Rady P, et al. Epidermodysplasia verruciformis and susceptibility to HPV. Disease Markers 2010;29(3-4):199-206.

[8] Nuovo G, Ishag M. The histologic spectrum of epidermodysplasia verruciformis. The American Journal of Surgical Pathology 2000;24(10):1400-6.

[9] Kanerva LO, Johansson E, Niemi KM, et al. Epidermodysplasia verruciformis. Clinical and lightand electron-microscopic observations during etretinate therapy. Arch Dermatol Res 1985;278(2):153-60.

[10] Segura S, Carrera C, Ferrando J, et al. Dermascopy in epidermodysplasia verruciformis. Dermatol Surg 2006;32(1):103-6.

[11] Majewski S, Jablonska S. Epidermodysplasia verruciformis of a model of human papillomavirusinduced genetic cancer of the skin. Arch Dermatol 1995;131(11):1312-8.

[12] Jablonska S, Obalek S, Wolska H. Follow-up of patients with epidermodysplasia verruciformis treated with etretinate. Dermatologica 1986;173(4):196-9.

[13] Heratizadeh A, Volker B, Kupsch E, et al. Successful symptomatic treatment of epidermodysplasia verruciformis with imiquimod 5\% cream. Hautarzt 2010;61(12):1052-5. 